\title{
Rectal-skin temperature difference in septicaemic newborn infants
}

\author{
J Messaritakis, D Anagnostakis, H Laskari, C Katerelos
}

\begin{abstract}
Serial skin (sole) and rectal temperatures were simultaneously taken from 55 healthy and 26 septicaemic newborn infants to find out prospectively whether septicaemic newborn infants have any thermoregulatory reaction to the septicaemia, and whether regular temperature measurements could help in the early diagnosis of septicaemia. The septicaemic infants were divided into three groups: the first comprised eight feverish infants, the second 11 with normal temperatures who were in relatively good clinical condition, and the third seven with normal temperatures who were in poor clinical condition. All 55 healthy babies had rectal temperatures of less than $37.8^{\circ} \mathrm{C}$ and a mean rectal-sole temperature difference of $2 \cdot 5^{\circ} \mathrm{C}$. The first group of septicaemic infants had rectal temperatures over $37.8^{\circ} \mathrm{C}$ and a high mean temperature difference of $6.9^{\circ} \mathrm{C}$, whereas the second group had rectal temperatures less than $37.8^{\circ} \mathrm{C}$ and a mean temperature difference of $4.7^{\circ} \mathrm{C}$. Infants of the third group had a low rectal temperature and a low mean temperature difference $\left(\mathbf{1} \cdot \mathbf{1}^{\circ} \mathrm{C}\right)$.

We conclude that septicaemic newborn infants show an adequate thermoregulatory reaction, which is reflected by a widening of the rectal-sole temperature difference of more than $3.5^{\circ} \mathrm{C}$, except for those who are critically ill, who lose this ability. In view of these results infants with normal temperatures but with a rectal-sole temperature difference of more than $3 \cdot 5^{\circ} \mathrm{C}$ should be suspected of septicaemia and investigated thoroughly.
\end{abstract}

Fever is a common sign of infection in children and adults. The regulation of body temperature at a raised point (fever) is achieved by two main mechanisms: firstly, increase of heat production by shivering or non-shivering thermogenesis and, secondly, decrease of heat dissipation, mainly by peripheral vasoconstriction. The end result of these mechanisms is a widening of the gap between the core (rectal) and skin temperature gradients. ${ }^{1-4}$

It is often said that newborn babies, and espe-

cially preterm ones, may not respond to infection with fever. We report data indicating that newborn babies, even those born prematurely, react to infection by widening the gap between the core and the skin temperature gradients, a phenomenon analogous to that seen in feverish children and adults.

\section{Patients and methods}

A total of 81 newborn infants were studied. Fifty five were healthy babies (group A) and the remaining 26 were septicaemic (group B). The diagnosis of septicaemia was made on the clinical picture and confirmed by positive cultures from blood or cerebrospinal fluid, or both, in 21 cases and by necropsy examination in five cases. All infants were studied between the fifth and the 12th day of life and, during the whole period of the study, all premature babies and those with septicaemia were nursed in incubators in an environment the temperature of which was regulated according to their weight and extrauterine age. ${ }^{5}$

Temperature measurements were made by a special tele-thermometer (Yellow Spring 43TA) and always by the same person (HL). The probe of the thermometer was inserted into the rectum to a depth of $5 \mathrm{~cm}$ in full term, and $4 \mathrm{~cm}$ in preterm babies and was left there for three minutes. ${ }^{6}$ Simultaneously the sole (skin) temperature was recorded by the special skin sensor of the instrument. The skin sensor was placed vertically over the sole and secured in place with a paper tape placed circumferentially around the foot.

During the study the 26 septicaemic infants (group B) were divided in three subgroups according to their clinical condition: group B1 comprised eight feverish infants (rectal temperature $>37 \cdot 8^{\circ} \mathrm{C}$ ); group B2 comprised 11 septicaemic babies who were not feverish (rectal temperature $<37 \cdot 8^{\circ} \mathrm{C}$ ) who were in comparatively good clinical condition; and group B3 comprised seven infants, who were not feverish but who were in a poor condition, and five of whom died.

Clinical data about the 81 infants are summarised in table 1 . Groups A and B are

Table 1 Comparability of the 81 newborn infants

\begin{tabular}{lllll}
\hline & $\begin{array}{l}\text { Group } A \\
(n=55)\end{array}$ & $\begin{array}{l}\text { Group } B 1 \\
(n=8)\end{array}$ & $\begin{array}{l}\text { Group B2 } \\
(n=I I)\end{array}$ & $\begin{array}{l}\text { Group } B 3 \\
(n=7)\end{array}$ \\
\hline Boys/girls & $31 / 24$ & $5 / 3$ & $6 / 5$ & $4 / 3$ \\
Fullterm/preterm & $23 / 32$ & $8 / 0$ & $4 / 7$ & $2 / 5$ \\
Mean (range) birth weight (g) & $235(1200-3850)$ & $3420(2710-4880)$ & $2310(1250-3980)$ \\
Mean (range) gestational age (weeks) & $36 \cdot 5(28-40)$ & $39 \cdot 5(38-43)$ & $36.9(29-40)$ & $\begin{array}{l}1750(1300-3100) \\
8.0(29-38)\end{array}$ \\
Mean age at temperature measurements (days) & 8 & $8 \cdot 9$ & $8 \cdot 5$ & 8.9 \\
\hline
\end{tabular}


comparable for weight, gestational age, sex, and extrauterine age at which temperature was taken.

\section{Results}

The rectal and sole temperatures, and the rectal-sole temperature differences are shown in table 2. It is of interest that all feverish septicaemic infants (group B) had a low sole temperature $\left(31 \cdot 8^{\circ} \mathrm{C}\right)$ and a big rectal-sole temperature difference $\left(6.9(1.5)^{\circ} \mathrm{C}\right)$, a result which was also true for group B2. In group B2, although the rectal temperature was similar to that of the healthy babies, the sole temperature was significantly lower than that of the healthy newborns; as a consequence the temperature difference $\left(4 \cdot 7(0 \cdot 8)^{\circ} \mathrm{C}\right)$ was much larger than that among the healthy babies $(p<0.001)$. In contrast, the temperature difference was low in the extremely ill septicaemic babies (group B3). In this group the sole temperature was almost the same as that of the healthy infants, but the rectal temperature was low.

Plotting our data graphically (figure) we see that if the infants with low rectal temperature (group B3) are excluded, only the healthy babies had a temperature difference of less than $3 \cdot 5^{\circ} \mathrm{C}$. All eight feverish septicaemic babies in group B1 as well as 10 of 11 septicaemic infants

Table 2 Mean $(S D)$ rectal and sole temperatures and rectal-sole temperature difference in the four groups of newborn infants (given as ${ }^{\circ} \mathrm{C}$ )

\begin{tabular}{llll}
\hline Group & $\begin{array}{l}\text { Rectal } \\
\text { temperature }\end{array}$ & $\begin{array}{l}\text { Sole } \\
\text { temperature }\end{array}$ & $\begin{array}{l}\text { Rectal-sole } \\
\text { temperature } \\
\text { difference }\end{array}$ \\
\hline A & $36.7(0.4)$ & $34.2(0.7)$ & $2 \cdot 5(0.5)$ \\
B1 & $38.7(0.7)$ & $31.8(0.4)$ & $6.9(1 \cdot 7)$ \\
B2 & $36.8(0.6)$ & $32.1(0.9)$ & $4 \cdot 7(0.8)$ \\
B3 & $34.8(0.4)$ & $33.7(0.7)$ & $1 \cdot 1(0.8)$ \\
\hline
\end{tabular}

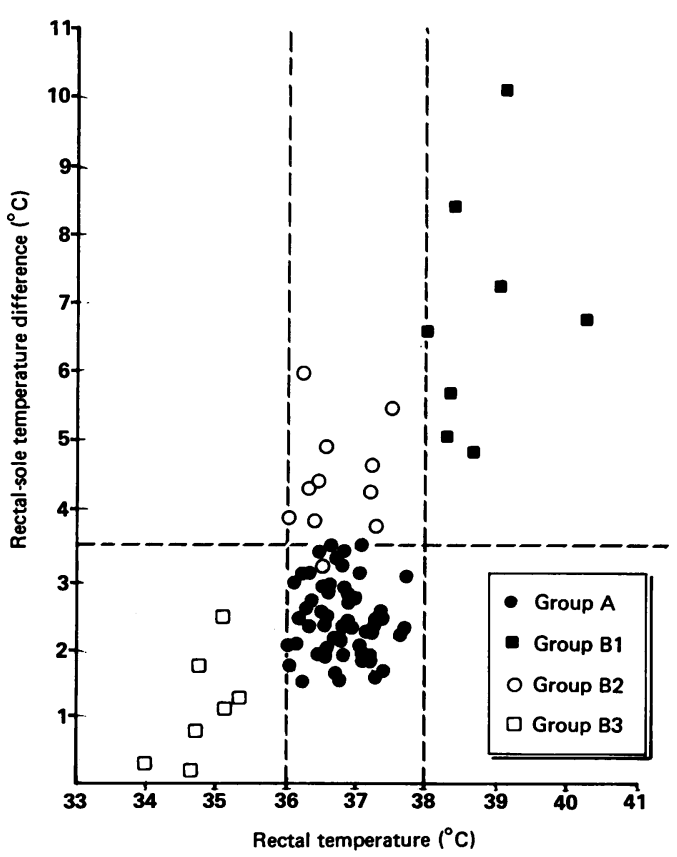

Rectal temperatures and rectal-sole temperature difference in all four groups of newborn infants. The horizontal dotted line shows the critical cut point of rectal-sole temperature difference of $3.5^{\circ} \mathrm{C}$ (see text). The vertical lines divide hypothermic, normothermic, and hyperthermic, neonates. with normal temperatures in group B2 had a temperature difference of more than $3.5^{\circ} \mathrm{C}$. In other words, only one of the $19(5 \%)$ septicaemic infants (groups B1+B2) had the same rectal-sole temperature difference as the healthy babies.

Interestingly, the above temperature measurements were also applied in another group of 21 infants (some born at full term and some preterm) in whom septicaemia was suspected both on clinical grounds and because of high white cell and differential counts, but in whom bacteria had not been isolated either from blood or from cerebrospinal fluid. Four of them were feverish and in good clinical condition, 14 had normal temperatures and were in relatively good clinical condition, and three had normal temperatures but were in a poor clinical condition. They all reacted in the same thermoregulatory manner as their counterparts with proved septicaemia. Four of them reacted in the same way as group B1, 11 in the same way as group $B 2$, and three in the same way as group B3.

\section{Discussion}

Our results show that most of our septicaemic infants had a good thermoregulatory reaction to septicaemia. Those in group B1 were able to increase their body temperature and to develop fever by increasing their heat production and by reducing their heat loss. It must be stressed that all these newborns were born at full term, and that their thermoregulatory reaction was analogous to that reported by Pomerance et al in their feverish babies born at full term. ${ }^{7}$

On the other hand the 11 septicaemic infants without temperatures in group B2 reacted with peripheral vasoconstriction in their effort to minimise heat loss and to preserve their internal core temperature within the normal range. This is why their rectal temperatures were normal, in contrast to their sole temperatures which were low. This means that the babies in this group showed an adequate thermoregulatory reaction, but not as efficient as that which was shown by those in group B1. Interestingly, almost two thirds of them were premature.

The mechanism of this prompt reaction in the septicaemic newborn infants is not exactly known. In endothermic organisms, such as in newborn and adult human beings, body temperature is controlled by a rather complicated thermoregulatory system. This may be described as a 'multi-input' system, in which temperature information from several sites of the body is fed into a central 'controller'. In this controller the temperature information is compared with a reference temperature value or set point. When the integrated body temperature is above or below the set point, effective mechanisms (such as vasoconstriction or vasodilation, extra heat production or sweat secretion) are stimulated to restore the temperature to its set point. ${ }^{8}$ During episodes of fever the set point is reset to a higher point. ${ }^{249}$

In this context it is not surprising that the feverish babies in group Bl reacted promptly by reducing heat loss by peripheral vasoconstriction, as their body temperature was raised. The 
analogous reaction of the babies with normal temperatures in group B2 deserves some comment, however. The vasoconstriction in these babies whose core (rectal) temperature did not differ from that of the healthy babies, is consistent with an upward deviation of the thermoregulatory set point. If this is true, one can speculate that some factor or factors (for example, bacterial pyrogen) may affect the set point in newborn babies. Whatever the mechanism, it is of interest that in most of the septicaemic infants, even those born prematurely, the thermoregulatory system reacted adequately.

In contrast, our seven critically ill septicaemic newborn babies with normal temperatures did not react with vasoconstriction, although their core (rectal) temperatures were low. This strongly suggests that such babies have no ability to mobilise their thermoregulatory mechanisms and are unable to conserve heat, which results in an appreciable drop of their core temperature. This must be considered as an ominous sign, as five of the seven who were unable to mobilise the mechanisms of their thermoregulatory systems, died within a few hours of their temperature measurements. An analogous thermoregulatory reaction was also shown by the 21 babies with possible (but not proved) septicaemia.

Although a high rectal-skin temperature difference may be caused by some other reasons (for example, poor cardiac output or hypovolaemia) our observations seem to indicate that this difference is a useful clinical sign in the diagnosis of septicaemia in newborn babies. The clinician should thoroughly investigate any newborn who is not feverish but has a rectalskin temperature difference of more than $3.5^{\circ} \mathrm{C}$.

1 Oliver TK. Temperature regulation and heat production in the newborn. Pediatr Clin North Am 1965;12:765-79.

Atkins E, Bodel P. Fever. N Engl f Med 1972;286:27-34. Kensch GT. Fever. To be or not to be. NY State $\mathcal{F}$ Med 1976; 11:1998-2001.

4 Kluger MJ. Fever. Pediatrics 1980;66:720-4.

5 Scopes J, Ahmed I. Range of critical temperature in sick and premature babies. Arch Dis Child 1966;41:417-9.

6 Karlberg P. The significance of depth of insertion of the thermometer for recording rectal temperature. Acta Paediatrica 1949;38:359-66.

7 Pomerance JL, Brand RJ, Meredith JL. Differentiating environmental from disease-related fevers in the term newborn. Pediatrics 1981;67:485-8.

8 Sinclair JC. Mechanisms of neonatal thermoregulation. In: Monset-Couchard M, Minkowski A, eds. Physiological and biochemical basis for perinatal medicine. Basle: Karger, 1981:180-6.

9 Bruck K. Thermoregulation: control mechanisms and neural processes. In: Sinclair JC, ed. Temperature regulations and energy metabolism in the newborn. New York: Grune and Stratton, 1978:120-5. 